\title{
Mixed Methods Research: An Overview for Beginner Researchers
}

\author{
Nur-E Hafsa \\ Faculty of Education, Department of Language and Literacy Education, University of Malaya, \\ 50603 Kuala Lumpur, Malaysia
}

\begin{abstract}
Mixed methods research design implicates merging or incorporating qualitative and quantitative research and data in a single study. Though the advantages of employing mixed methods are convincing, the methodology has some shortcomings. Lack of time, energy and resources pose main obstacles behind not undertaking mixed methodology as research design. Other than the operational issues there are criticisms regarding the philosophical underpinning and research method typologies. However, as this methodology is the combination of two dominant research genres, it has the potential to offset the shortcomings of one single method and therefore, offers more validity and reliability to the findings of a research. The aim of this article is to acquaint the beginner researchers with the pros and cons of mixed methods research which has an immense potentiality to be employed in various fields of academia including social sciences, health science, and technology.
\end{abstract}

Keywords: Mixed methods research, philosophical underpinning, rationale, controversy, potentiality.

DOI: $10.7176 / J L L L / 58-05$

Publication date:July $31^{\text {st }} 2019$

\section{Introduction}

Mixed methods research design implicates merging or incorporating qualitative and quantitative research and data in a single study (Creswell, 2014). Qualitative data is derived from open ended sources usually without predesigned replies whereas quantitative data comes from close ended data sources like tests, questionnaires or psychological instruments (Creswell, 2014).Various expressions are in use for this approach, such as "integrating, synthesis, quantitative and qualitative methods, multimethod, and mixed methodology" but in contemporary writings the commonly used term is - mixed methods (Bryman, 2006; Tashakkori \& Teddlie, 2010).

Hanson, Creswell, Clark, Petska, \& Creswell (2005, pp. 224) provide a more rigid and operational definition of mixed method research as "the collection, analysis, and integration of quantitative and qualitative data in a single or multiphase study". Tashakkori and Creswell (2007a, p.2) defined mixed method research project in more elaborated terms focusing on the necessity of manifestation of merging in every step:

"Research in which the investigator collects and analyzes data, integrates the findings, and draws inferences using both qualitative and quantitative approaches in a single study or program of inquiry".

In other words, good quality mixed methods research entails mixing at all stages of the study- from phrasing research questions, to sampling, to data collection, to analysis, and, finally, to interpretation (Yin, 2006). As mixed method researchers adopt a "non-purist or compatibilist or mixed position" (Johnson \& Onwuegbuzie, 2004, pp.15) it offers the scope of blending various research design constituents to seek the best solution to their precise research problem.

The objective of this article is to provide an overview on mixed methods research for beginner researchers planning to embark on mixed methods study. This overview incorporates sections on- (i) classifications of Mixed Methods Research (MMR), (ii) philosophical underpinning of MMR, (iii) rationale for adopting MMR, and (iv) criticism of employing MMR as research design. The overall aim of this article is to acquaint the beginner researchers with the various aspects related to mixed methods research which as a research genre has an immense potentiality to be employed in various fields of academia including social sciences, health science, and technology etc.

\section{Classifications of MMR}

A brief description of the three major categories of mixed methods designs in social sciences is provided by Creswell (2014) in the following manner:

\subsection{Convergent parallel mixed methods}

In this research design the researcher "converges or merges" quantitative and qualitative data to derive a holistic inquiry of the research question. The researcher usually accumulates qualitative and quantitative data almost simultaneously and then incorporates the data in the interpretation stage of the result. In this design inconsistencies or contrasting findings are clarified or further explored.

\subsection{Explanatory sequential mixed methods}

In this research design the researcher first executes the quantitative inquiry of the study, analyzes the results and 
then explains the results more elaborately taking aid of the qualitative data. This design is termed as explanatory because the data gathered from the quantitative sources are further elucidated in the light of the qualitative data gathered in the later stage. This design is termed as sequential because the preliminary quantitative stage is followed by the qualitative stage. This type of study is widely accepted in studies with strong quantitative alignment.

The challenge of this type of study is- finding out or detecting the quantitative results to further examine and the uneven sample size for each stage of the study.

\subsection{Exploratory sequential mixed methods}

In exploratory sequential mixed methods design the order of investigation is quite inverse to the explanatory sequential mixed methods study. In this design the researcher initiates the study with the qualitative phase to collect the viewpoints of the participants. Analysis of the data then is used to structure the quantitative phase. The qualitative phase facilitates constructing an instrument suitable for the sample of the study, seeking out fitting instruments to use in the quantitative stage, or to identify variables to use in the quantitative stage.

The challenging factor of using this model is-concentrating on the precise qualitative findings to employ and select the sample for both stages of the study.

More sophisticated versions of these three basic designs can be found in the following research designs.

\subsection{Transformative mixed methods design}

Transformative mixed methods design uses "social justice" or "power" as the umbrella concept incorporating in it both quantitative and qualitative data. In this type of study data can be arranged simultaneously or successively to facilitate building up of one data set based on other.

\subsection{Embedded mixed methods design}

The central concept of embedded mixed methods design is- either qualitative or quantitative data is nested within a bigger design- like an experiment and the data sources serve a facilitating part in the whole design.

\subsection{Multiphase mixed methods design}

Multiphase mixed methods design is prevalent in the areas of evaluation and program interventions. In this type of design, concurrent or sequential approaches are applied jointly to get the best sense of a long-term program objective.

\section{Philosophical underpinning of Mixed Methods Research}

Cherryholmes (1992), Morgan (2007) and Creswell (2014) regarded Pragmatism as the philosophical foundation for Mixed Methods research. The term "pragmatism" originates from the Greek noun "pragma" which means "works or deeds" (Steyen et al., 1986, p.101; Landman et al., 1990, p.74; De Vries, 1986, p.135).

Pragmatism, also known as experimentalism is a philosophy that

- Considers the rationality of ideas by their results when put into practice/ real life.

- Inspires to look for the way outs and actions that guide us to reach our desired goal (Ornstein and Levin, 1999, p. 98).

The source of pragmatism can be found in the ideas of the ancient Greek philosopher, Protagoras from Abdera (485-415 BC), who confronted the ideology of "absolute truth" (Engelbrecht et al., 1989, p. 116; De Vries, 1986, p. 135). Protagoras used to believe that true ideas must be provable in real situations (Engelbrecht et al., 1989; De Vries, 1986). Pragmatism developed through the writings of Charles Sanders Peirce, William James, Mead, and John Dewey (Cherryholmes, 1992). Other remarkable writers of the genre are Murphy (1990), Patton (1990), and Rorty (1990).

Pragmatism deals with the implementation of -"what works" and finding way out from difficulties (Patton, 1990). Researchers following this tradition focus on the research problem rather than concentrating on methods or procedures and utilize all approaches in hand to probe into the issue (Rossman \& Wilson, 1985).

Cherryholmes (1992), Morgan (2007) and Creswell (2014) has justified pragmatism as the philosophical foundation for mixed methods research in the following terms:

- Pragmatism does not limit itself to any specific epistemology or ontology. Following this philosophical viewpoint, researchers pursuing mixed methods employ both qualitative and quantitative standpoints to accomplish their target or goal.

- Philosophy of pragmatism offers the researchers a flexibility in terms of choosing methods, techniques, and procedures of research that best suit their necessities and objectives.

- To the pragmatists the world is not an "absolute unity". Therefore, mixed method researchers rely on various approaches for data collection and analysis rather than affiliating to either qualitative or quantitative genre. 
- Pragmatists define truth as- what serves the purpose at the time. Likewise mixed methods researchers exploit both qualitative and quantitative data to provide the most comprehensive view of their research question.

- Mixed method researchers need to clarify the objectives of qualitative and quantitative data synthesis.

- Pragmatists believe research always takes place in social, historical, political, and other backdrops. Therefore, mixed method studies may comprise of a postmodern essence echoing social justice and political objectives.

- Therefore, for the mixed method researcher pragmatism facilitates employing various methods, diverse worldviews, along with various types of data collection and analysis techniques.

Morgan (2007), Patton (1990) and Tashakkori and Teddlie (2010) express the significance of Pragmatism as the philosophical underpinning for mixed methods research for its capacity to emphasize on research problem in social sciences research and then adopting diverse approaches to resolve the inquiry. The basic assumption of mixed methods research is utilizing multiple data sources to ensure a holistic understanding of the research problem rather than depending on a single research design- qualitative or quantitative (Creswell, 2014).

\section{Rationale for adopting MMR}

Seven frequently mentioned aims found for adopting mixed methods were specified by Tashakkori and Newman (2010):

- Complementarity- to blend in two diverse but related responses to a single research question using both quantitative and qualitative approaches.

- Completeness-for achieving a holistic view of the phenomenon studied in the research by integrating findings from quantitative and qualitative investigation.

- Development- to utilize the initial phase of the investigation to develop the research questions, data sources or sampling decisions necessary for the later phase of the study.

- Expansion- to expand the findings derived from the first phase of the investigation.

- Corroboration/confirmation- to validate the quality of conclusions derived from one type of study by checking it against mixed designs.

- Compensation- to balance the shortcomings of one method utilizing the supremacy of the other method.

- Diversity- to analyze the varied depictions of the same phenomenon.

The validity and reliability of qualitative results of a mixed methods study augments as the sample of the qualitative phase is derived generally from the quantitative sample (Hesse-Biber, 2014). If identical questions are enquired in both the phases, concern for validity and reliability of research outcomes can be addressed by ensuring - (1) the degree to which research outcomes from identical questions produce identical responses (reliability) and (2) the degree to which their responses seem to address the same fundamental problems to produce an overall unanimity of responses (validity through triangulation) (Hesse-Biber, 2014).

\section{Criticism of employing MMR as research design}

Though the advantages of employing mixed methods are convincing, the methodology has some shortcomings. Johnson and Onwuegbuzie (2004) conclude that adopting mixed methodology can be daunting to researchers because of shortage of - resources, time and knowledge, especially if the study is a concurrent mixed study. Zou, Sunindjio \& Dainty (2014) also identify lack of time, energy and resources as the main obstacles behind not undertaking mixed methodology as research design. Other than the operational issues there are criticisms regarding the philosophical underpinning and research method typologies (Fiorini, Griffiths, Houdmont, 2016).

\subsection{Philosophical issues versus research method typologies: some Controversies}

In spite of being a key to overcome the shortcomings of applying either qualitative or quantitative research method, MMR has faced tremendous condemnation (Zou, Sunindijo, \& Dainty, 2014). Bryman (2012) mentioned two significant issues against the application of MMR:

- The first issue centres on the epistemological (the theory of knowledge including its method, validity, and scope) juxtaposition of two contrasting philosophical stances inherent in mixed methods research. For instance, the constructivist school of research which is commonly aligned with qualitative research genre considers reality as socially made by and between the people experiencing it. Therefore, reality is taken as subjective and need not be shared by others (Darlaston-Jones, 2007). On the contrary, positivism which is usually aligned with quantitative research methods, views reality as measurable, objective and worldwide. Hence reality is believed to be same for everyone and with the help of science this common reality can be traced and quantified (Darlaston-Jones, 2007).

- Secondly, it is argued on the ground that qualitative and quantitative are two quite distinct branches of research. For instance, quantitative research embodies an objective role of the researcher, a deductive 
approach (theory a priori) to test theories, and a well-organized structure to collect and analyze data to develop a generalizable finding. In contrast, qualitative research proposes a subjective role of the researcher, holds an inductive (theory a posteriori) approach in developing theory, collecting data in a comprehensive way to obtain a subjective, in depth understanding of a phenomenon (Antwi \& Hamza, 2015).

As pragmatism focuses on what "works" philosophy and accordingly utilizes both objective and subjective knowledge, it has been mentioned by a considerable number of researchers (e.g. Cameron, 2009; Cronholm \& Hjalmarsson, 2011; Johnson et al., 2007; Morgan, 2007) as the most appropriate philosophical approach for mixed methods researches (Johnson \& Onwuegbuzie, 2004; Morgan, 2007). Pragmatism rebuts the criticisms by the methodological conformists that quantitative and qualitative methods belonging to two completely diverse genre cannot be incorporated (Fiorini, Griffiths, \& Houdmont, 2016). In principle, pragmatism considers the advantages and disadvantages of different research methodologies as complementary (Cronholm \& Hjalmarsson, 2011) and inter-reliant, keeping in account the benefits of integrating two distinct methods to offset the probable drawbacks of each other (Scott, McCone, Sayegh, Looney, \& Jackson, 2011).

However, the application of pragmatism in mixed methods research is not beyond criticism. Greene (2008) opined that research should be undertaken to comprehend how the philosophical beliefs of pragmatism effect the enquiry issues. Hall (2013) mentioned the complexity of identifying the mixed methods design which "works" before applying it.

Though, pragmatism is most widely accepted paradigm among the mixed method researchers, different versions of it exist (Teddlie \& Tashakkori, 2010). Two types of pragmatism adopted by mixed method researchers are-adopting an a-paradigmatic stance or a multiple paradigm approach (Hall, 2013). Adopting an aparadigmatic stance refers to bypassing the paradigm issue on the ground that methodology and epistemology are not related to each other. Hall (2013) criticized this approach on the basis that epistemology plays a significant role in the interpretation stage of gathered data.

Teddlie and Tashakkori (2010) categorized the multiple paradigm approach in three different types, namely-the complementary strength stance, the dialectical stance, and the multiple paradigms stance. All these stances emphasize the advantages of applying multiple paradigms to comprehend a single phenomenon but the modes of operation of these methods vary from each other.

\section{Conclusion}

Mixed methods research is widely discussed and applied in academia because of its wide variety, much debated philosophical alignment, and advantages and disadvantages associated with it. As this methodology is the combination of two dominant research genres it has the potential to offset the shortcomings of one single method and therefore, offers more validity and reliability to the findings of a research. This methodology is difficult to handle by beginner researchers due to the time, resource, and expertise factors associated with it. However, this methodology is embraced in academia for its potentiality to serve various complex research issues:

Today's research world is becoming increasingly inter- disciplinary, complex, and dynamic; therefore, many researchers need to complement one method with another, and all researchers need a solid understanding of multiple methods used by other scholars to facilitate communication, to promote collaboration, and to provide superior research (Johnson \& Onwuegbuzie, 2004, pp.15).

\section{Acknowledgement}

My gratitude and special thanks to Dr. Zuwati Hasim, Senior Lecturer, Faculty of Education, Department of Language and Literacy Education, University of Malaya, Kuala Lumpur for providing valuable feedback on this article.

\section{References}

Antwi, S. K., and Hamza, K. (2015), "Qualitative and quantitative research paradigms in business research: a philosophical reflection”, European Journal of Business and Management (7), 215-225.

Bryman, A. (2006). Mixed methods: A four-volume set. Thousand Oaks, CA: Sage.

Bryman, A. (2012). Social Research Methods. 4th ed. Oxford: Oxford University Press.

Burke Johnson, R., and Onwuegbuzie, A. J. (2004), "Mixed Methods Research: A Research Paradigm Whose Time Has Come", Educational Researcher 33 (7), 14-26.

Cameron, R. (2009), "A sequential mixed model research design: design, analytical and display issues", International Journal of Multiple Research Approaches 3 (2), 140-152.

Cherryholmes, C. H. (1992), "Notes on pragmatism and scientific realism", Educational Researcher, 13-17.

Creswell, J. W. (2014). Research design: qualitative, quantitative, and mixed methods approaches. 4th edn. United States of America: SAGE Publications, Inc.

Cronholm, S., \& Hjalmarsson, A. (2011), "Experiences from sequential use of mixed methods", The Electronic 
Journal of Business Research Methods 9 (2), 87-95.

Darlaston-Jones, D. (2007), "Making connections: the relationship between epistemology and research methods", The Australian Community Psychologist 19 (1), 19-27.

Engelbrecht, S. W. B., Yssel, J. C., Griessel, G. A. G., \& Verster, T. L. (1989). In Education III: Pretoria: Via Afrika.

Fiorini, L., Griffiths, A., \& Houdmont, J. (2016), "Mixed methods research in the health sciences: a review", Malta Journal of Health Sciences, available at DOI:10.14614/MIXMETHRES/7/16, accessed on June 30, 2018.

Greene, J. C. (2008), "Is mixed methods social inquiry a distinctive methodology?", Journal of Mixed Methods Research 2(1), 7-22.

Hall, R. F. (2013). 'Mixed methods: in search of a paradigm' in T. Lê \& Q. Lê (Eds.), Conducting Research in a Changing and Challenging World. New York: Nova Science Publishers Incorporated, pp. 71-78.

Hanson, W. E., Creswell, J. W., Plano Clark, V. L., Petska, K. S., \& Creswell, J. D. (2005), "Mixed methods research designs in counseling psychology", Journal of Counseling Psychology 52, 224-235.

Hesse-Biber, S. N. (2014). 'Interpretative Approaches to Mixed Methods Research' in Mixed methods research: merging theory with practice. Guilford Publications.

Johnson, R. B., Onwuegbuzie, A. J., \& Turner, L. A. (2007), "Toward a definition of mixed methods research", Journal of Mixed Methods Research 1(2), 112-133.

Landman, W. A., Van der Merwe, I. J. M., Pitout, D. N., Smith, A. G., \& Windell, J. H. J. (1990). Teacher's Handbook for Education. Pretoria Van Schaik.

Morgan, D. L. (2007). "Paradigms lost and pragmatism regained. Methodological implications of combining qualitative and quantitative methods", Journal of Mixed Methods Research 1(1), 48-76.

Murphy, J. P. (1990). Pragmatism: From Peirce to Davidson: Boulder, CO: Westview.

Patton, M. Q. (1990). Qualitative evaluation and research methods (2nd ed.): Newbury Park, CA: Sage.

Rorty, R. (1990). Pragmatism as anti-representationalism. In Pragmatism: From Peirce to Davison (p. 1-6): Boulder, CO: Westview.

Rossman, G. B., \& Wilson, B. L. (1985). Numbers and words: Combining quantitative and qualitative methods in a single large-scale evaluation study, Evaluation Review 9 (5), 627-643.

Scott, W. J., McCone, D. R., Sayegh, L., Looney, J. D., \& Jackson, R. J. (2011). "Mixed methods in a post deployment study of U.S. Army National Guard soldiers", Journal of Workplace Behavior Health 26 (4), 275-295

Steyn, P. D. G., Behr, A. L., Bisschoff, T. C., \& Vos, A. J. (1986). Education 3: The philosophical and historical foundation of education: Cape Town: Maskew Miller Longman.

Tashakkori, A., \& Creswell, J. W. (2007a). "The new era of mixed methods", Journal of Mixed Methods Research 1, 3-7.

Tashakkori, A., \& Newman, I. (2010). 'Mixed methods: integrating quantitative and qualitative approaches to research' in McGaw, B., Baker, E. \& Peterson, P. P. (Eds.), International Encyclopedia of Education (3rd ed., p. 514520). Oxford, U.K.: Elsevier.

Tashakkori, A., \& Teddlie, C. (2010). SAGE handbook of mixed methods in social and behavioral research. 2nd ed. Thousand Oaks, CA: Sage.

Yin, R. K. (2006). "Mixed methods research: Are the methods genuinely integrated or merely parallel?" Research in the Schools 13, 41-47.

Zou, P. X. W., Sunindijo, R. Y., \& Dainty, A. R. J. (2014). "A mixed methods research design for bridging the gap between research and practice in construction safety", Safety Science 70, 316-326. 